\title{
Ação da inoculação de hemolinfa no mecanismo de defesa de Biomphalaria tenagophila (Orbigny, 1835)*
}

\author{
The effect of hemolymph inoculation on the defense mechanism of Biomphalaria \\ tenagophila (Orbigny, 1835)
}

\author{
Soely Maria Pissini Machado Reis, Luiz Augusto Magalhães, \\ José Ferreira de Carvalho
}

\author{
Bolsista da FAPESP - Campinas, SP - Brasil (S. M. P. M. R.) \\ Departamento de Parasitologia, Instituto de Biologia da Universidade Estadual de Campinas \\ (UNICAMP) - Campinas, SP - Brasil (L. A. M.) \\ Departamento de Estatística do Instituto de Matemática, Estatistica e Ciências da Computação \\ da Universidade Estadual de Campinas (UNICAMP) - Campinas, SP - Brasil (J. F. C.)
}

\begin{abstract}
Estudou-se a resistência à infecção pelo $S$. mansoni em moluscos B. tenagophila inoculados com vários tipos de hemolinfa provenientes de moluscos infectados por $S$. mansoni da linhagem SJ ou por outros trematódeos avaliando-se, nestas circunstâncias, o comportamento dos amebócitos. Concluiu-se que dois tipos de mecanismos teriam agido provocando resistência à infecçāo pelo $S$. mansoni: celular $\theta$ humoral. A reaçāo do tipo celular ocorreu quando os moluscos eram inoculados com hemolinfa de moluscos infectados por $S$. mansoni $B$. tenagophila inoculadas com hemolinfa de moluscos infectados por furcocercárias longifurcadas sem ocelos, apresentaram elevada resisténcia à infecçảo posterior por S.mansoni.
\end{abstract}

Biomphalaria, parasitologia. Schistosoma mansoni, patogenicidade.

\section{Introdução}

Moluscos planorbídeos podem ser hospedeiros intermediários de várias espécies de trematódeos digenéticos que parasitam, na fase adulta, mamíferos, aves, peixes, anfíbios e répteis. O parasitismo concomitante em moluscos pode levar a uma incompatibilidade entre estágios de larvas de determinadas espécies de trematódeos (Lim e Heyneman ${ }^{9}$, 1972). Esses autores, ao se referirem ao fenômeno citado, utilizaram o termo "antagonismo".

No interior dos moluscos as larvas de trematódeos podem interagir atraves de mecanismos diretos e indiretos. Lie e col. ${ }^{4}$ (1975) citam, como exemplo de antagonismo direto, a predaçāo das rédias sobre outras larvas de trematódeos. Como exemplo de antagonismo indireto, destacam-se: a) ação citotóxica mediada por enzimas lisossomais que mata ou lisa as células de parasitas; b) competição alimentar ou luta por espaço vital; c) ação imunológica com participação de células amebocitárias e componentes humorais (Lie e Heyneman ${ }^{3,5,6}, 1975,1976$; Lie e col. $^{7}, 1980$; e Lie ${ }^{8}$, 1982).

Estudos realizados anteriormente, pela mesma equipe, (Machado e col. ${ }^{11}, 1988$ ) em infecções concomitantes de diferentes espécies de trematódeos em Biomphalaria tenagophila, permitiram observar que a infecçāo natural de moluscos foi frequentemente mono-específica. Entretanto, houve eventual concomitância de equinostomocercárias com furcocercárias dotadas de ocelos. Verificou-se também a presença concomitante de furcocercárias sem ocelos. Moluscos naturalmente infectados com equinostomocercárias e distomocercárias com acúleo apresentaram resistência parcial ao desenvolvimento do Schistosoma mansoni nas tentativas de superinfecção experimental, com índices de resistência, respectivamente, de $73 \%$ e $87 \%$. Os resultados encontrados (Machado e col. ${ }^{11}, 1988$ ) mostraram que as larvas de $S$. mansoni não se desenvolveram em moluscos naturalmente infectados com furcocercárias longifurcadas com ocelos ou com furcocercárias

*Trabalho realizado com auxílio da FAPESP - Processo n' 88/2336-2.

Separatas/Reprints: Luiz Augusto Magalhäes - Depatamento de Parasitologia, Instituto de Matemática, Estatística e Ciências da Computaçāo da Universidade Estadual de Campinas - Caixa Postal 6109-13081-970 - Campinas, SP - Brasit

Ediçāo subvencionada pela FAPESP. Processo 95/2290-6.

Recebido em 17.1.1995. Aprovado em 12.4.1995. 
longifurcadas sem ocelos. A ausência de reação amebocitária em torno das larvas destruídas de $S$. mansoni nos moluscos infectados, pareceu indicar que, nesses casos, não houve participação de amebócitos nos mecanismos da resistência observada ao desenvolvimento dos esporocistos.

Tendo em vista essas observaçoes, o presente trabalho objetiva esclarecer as seguintes questōes: 1) Moluscos de laboratório, não infectados, apresentariam resistência à infeç̧ão pelo $S$. mansoni apos inoculados com hemolinfa de moluscos naturalmente infectados por outros trematódeos ou com hemolinfa de moluscos experimentalmente infectados por S. mansoni? 2) Como se comportariam esses moluscos quando a hemolinfa de moluscos infectados fosse inoculada logo após à infecção experimental pelo $S$. mansoni? 3) Qual seria o comportamento dos amebócitos frente às infecçōes e as inoculaçoes de hemolinfa?

\section{Materlal e Mótodo}

Foram formados os seguintes grupos de Biomphalaria tenagophila para o cálculo da taxa de infecção experimental por Schistosoma mansoni (45 moluscos por grupo), para a contagem de amebóticos na hemolinfa ( 91 moluscos por grupo) e para o preparo de cortes histológicos e cálculo de penetraçāo de miracídios (15 moluscos por grupo):

Grupo 1 - moluscos livres de infecção (controle sadio).

Grupo 2 - moluscos livres de infecção, anestesiados com mentol (controle anestesiado). Grupo 3 - moluscos infectados experimentalmente por $S$. mansoni (controle infectado).

Grupo 4 - moluscos inoculados com hemolinfa de moluscos não portadores de larvas e posteriormente infectados por S.mansoni.

Grupo 5 - moluscos inoculados com hemolinfa de moluscos portadores de larvas de $S$. mansoni e posteriormente infectados por $S$. mansoni.

Grupo 6 - moluscos inoculados com hemolinfa de moluscos portadores de distomoxifidiocercárias e posteriormente infectados por $S$. mansoni. Grupo 7 - moluscos inoculados com hemolinfa de moluscos portadores de furcocercárias longifurcadas sem ocelos e posteriormente infectados por S. mansoni.

Grupo 8 - moluscos infectados por $S$. mansoni e logo após inoculados com hemolinfa de moluscos não portadores de larvas.

Grupo 9 - moluscos infectados por $S$. mansoni e logo após inoculados com hemolinfa de moluscos portadores de distomoxifidiocercárias.

Grupo 10 - moluscos infectados por S. mansoni e logo após inoculados com hemolinfa de moluscos portadores de furcocercárias longifurcadas sem ocelos.
Foram utilizadas B. tenagophila nascidas no laboratório, provenientes de populaçōes obtidas de criadouros naturais no Vale do Rio Paraíba do Sul, Estado de Såo Paulo. Para a obtenção de moluscos naturalmente infectados por larvas de outros Digenea, coletaram-se exemplares de $B$. tenagophila em um criadouro de peixes ornamentais situado em Louveira, SP. Seguramente esse criadouro não se constituía em foco de $S$. mansoni. As coletas foram realizadas em 1988 e 1989.

A hemolinfa foi coletada mediante punção da região cefalopodal com uma seringa esterilizada do tipo tuberculina. A hemolinfa foi retirada de moluscos com diâmetro entre 13 a $18 \mathrm{~mm}$ e mantida em tubo plástico no gelo até o instante do uso (Santana e col. $^{12}, 1985$ ).

Para a contagem de amebocitos e estudo morfologico dessas células, a hemolinfa foi utilizada logo após sua obtenção. Utilizou-se a câmara de Neubauer para a contagem de ameb6citos; esta foi feita individualmente em 7 exemplares de cada grupo para cada intervalo de tempo. Considerou-se a média de células por $0,1 \mathrm{ml}$ de hemolinfa. Para a classificação dos amebócitos adotou-se o critério mais difundido: amebócitos não estrelados (hialinócitos) e amebócitos estrelados (granulócitos).

Para a infeç̧ăo experimental dos moluscos ao $S$. mansoni foram utilizados exemplares de 7 a $10 \mathrm{~mm}$ que foram expostos individualmente a 10 miracídios da linhagem SJ. Os moluscos destinados ao exame histológico e ao cálculo de penetração das larvas foram expostos a 100 miracídios. As preparaçðes histologicas foram obtidas em moluscos fixados em Bouin aquoso, incluídos em parafina, cortados em micrótomo ( 7 micra) e corados pelo trictômico de Gomori. Os moluscos foram sacrificados $2,12,16$, 18 e 24 horas ap6s a exposição ao $S$, mansoni.

Para a verificação da taxa de infecção dos moluscos, estes foram expostos individualmente à luz e ao calor provenientes de lâmpada elétrica de $60 w$ durante duas horas. Após a exposição, os frascos contendo os moluscos foram examinados em lupa estereoscópica para a procura e identificação de cercárias.

A análise estatística dos valores obtidos nas contagens de células da hemolinfa, no número de exemplares infectados quando da exposição ao $S$. mansoni e na avaliação quantitativa de esporocistos degenerados presentes nos cortes histológicos, foi efetuada pelo teste de Fisher ${ }^{2}$ (1961) e pelo método de comparaçăo de duas proporçőes independentes.

\section{Resultados}

Em 1.072 moluscos capturados no campo foram encontrados 37 contendo furcocercárias longifurcadas sem ocelos $(3,4 \%)$ e 25 contendo distomoxifidiocercárias $(2,3 \%)$, sempre em infeç̧ões monoespecíficas. 
Os resultados numéricos referentes às taxas de infecção dos moluscos expostos, experimentalmente ao $S$. mansoni, constam da Tabela 1 . A taxa de penetração dos miracídios e a viabilida. de dos esporocistos estăo na Tabela 2. Os dados referentes à contagem dos amebócitos constam das Tabelas 3 a 7.

Os moluscos pertencentes aos grupos $3,4,6,8$ e 10 começaram a eliminar cercárias no $37^{\circ}$ dia após a infecção experimental por $S$ mansoni. Moluscos dos grupos 5, 7 e 9 iniciaram a eliminação de cercárias no $52^{\circ}$ dia após a infecção. Houve, portanto, um retardo no desenvolvimento das larvas de $S$. mansoni quando os moluscos receberam hemolinfa de caramujos infectados por $S$. mansoni ou por furcocercárias longifurcadas sem ocelos anteriormente à infecção por $S$. mansoni. A inoculação de moluscos com hemolinfa de caramujos infectados com distomoxifidiocercárias retardou o desenvolvimento das larvas de $S$. mansoni, quando aplicada logo após a infeç̧̃̃o pelo $S$. mansoni.

Nos moluscos anestesiados com mentol observouse elevação do número de amebócitos nas primeiras horas. Nos moluscos somente infectados por S. mansoni (controle infectado) houve um significativo aumento dos amebócitos estrelados às $18 \mathrm{~h}$ após a infeç̧ão com relação aos grupos que apresentaram maiores taxas de infecção. No grupo 4 não se observou aumento significativo do número de células estreladas na hemolinfa circulante com relação ao grupo-controle (grupo 3). A elevação das células estreladas foi tardia nos grupos 6,8 e $9 \mathrm{e}$ precoce no grupo 10.

Nos grupos que apresentaram maior resistência à infecção pelo $S$ mansoni (grupos 5 e 7), a elevação do número de amebócitos estrelados foi precoce com relação ao grupo-controle infectado. Neste grupo houve nítida reaçāo amebocitária em torno dos esporocistos. Nos grupos experimentais verificou-se que somente os moluscos inoculados com hemolinfa de caramujos infectados com $S$. mansoni e submetidos a reinfecção apresentaram forte reação amebocitátia em torno dos esporocistos, acompanhada de grande número de esporocistos degenerados. Nesses casos a reação amebocitária nos tecidos foi precoce. Nos outros grupos, essa reação foi discreta o que não impediu que se observasse grande número de esporocistos degenerados no grupo 7 .

Tabela 1 - Taxas de infecção de B. tenagophila expostas ao S. mansoni quando inoculadas com hemolinfa de moluscos infectados ou não infectados por $S$. mansoni ou outros digenéticos.

\begin{tabular}{clrr} 
Grupos experimentais & \multicolumn{2}{c}{$\begin{array}{c}\text { Tipo de hemolinfa inoculada } \\
\text { Época da inoculação }\end{array}$} & $\begin{array}{r}\text { Taxa de infecção } \\
\text { por S. mansoni }\end{array}$ \\
\cline { 2 - 3 } & Anterior à infecção & Posterior à infecção & 38,5 \\
\hline 3 & sem larvas & 48,7 \\
5 & com S. mansoni & 20,0 \\
6 & com & 43,2 \\
7 & distomoxifidiocercária & 24,2 \\
8 & com furcocercária & sem larvas & 48,5 \\
9 & longifurcada & com & 48,5 \\
10 & & distomoxifidiocercária & \\
& & com furcocercária & 41,2 \\
& & longifurcada
\end{tabular}

Tabela 2 - Taxas de penetração de miracidios e viabilidade de esporacistos de S.mansoni em B.tenagophila expostas a 100 miracidios de S. mansoni e inoculadas com hemolinfa de moluscos livres de infecção ou portadores de larvas de digenéticos.

\begin{tabular}{lllll}
\multirow{2}{*}{$\begin{array}{l}\text { Grupos } \\
\text { experimentais }\end{array}$} & $\begin{array}{l}\text { Taxa de } \\
\text { penetração dos } \\
\text { miracídios }\end{array}$ & \multicolumn{2}{c}{ Número médio de esporocistos } & \multirow{2}{*}{\begin{tabular}{l} 
Taxa de \\
esporacistos \\
\cline { 3 - 4 } degenerados
\end{tabular}} \\
\cline { 2 - 4 } & 10,3 & Íntegros & Degenerados & 45,1 \\
\hline 3 & 10,6 & 17 & 14 & 43,7 \\
4 & 10,3 & 7 & 14 & 77,4 \\
5 & 10,6 & 17 & 24 & 47,0 \\
6 & 10,3 & 9 & 15 & 71,0 \\
7 & 10,6 & 16 & 22 & 50,0 \\
8 & 10,3 & 14 & 16 & 54,8 \\
9 & 10,3 & 15 & 17 & 51,6
\end{tabular}


Tabela 3 - Número médio de amebócitos circulantes em $B$. tenagophila dos grupos 1 e 2 .

\begin{tabular}{|c|c|c|c|c|c|c|}
\hline \multirow{2}{*}{$\begin{array}{l}\text { Intervalo } \\
\text { (horas) }\end{array}$} & \multicolumn{3}{|c|}{ Grupo 1} & \multicolumn{3}{|c|}{ Grupo 2} \\
\hline & $\overline{\mathrm{AE}}$ & $\overline{\mathrm{ANE}}$ & $\overline{\text { AT }}$ & $\overline{\mathrm{AE}}$ & ANE & AT \\
\hline$\overline{0,5}$ & $5,6 \pm 4,8$ & $11,6 \pm 3,9$ & $17,2 \pm 8,5$ & $25,7 \pm 9,2$ & $12,0 \pm 5,8$ & $37,7 \pm 7,3$ \\
\hline 2 & $6,3 \pm 5,2$ & $8,6 \pm 4,2$ & $14,9 \pm 8,8$ & $21,1 \pm 10,4$ & $15,1 \pm 9,2$ & $36,2 \pm 9,4$ \\
\hline 4 & $3,3 \pm 1,9$ & $7,9 \pm 4,2$ & $11,2 \pm 4,9$ & $17,9 \pm 3,0$ & $15,4 \pm 5,0$ & $33,3 \pm 4,5$ \\
\hline 6 & $4,7 \pm 2,9$ & $6,7 \pm 3,0$ & $11,4 \pm 4,6$ & $19,1 \pm 7,1$ & $11,8 \pm 6,6$ & $30,9 \pm 10,9$ \\
\hline 8 & $6,1 \pm 7,7$ & $12,4 \pm 7,2$ & $18,5 \pm 14,1$ & $16,7 \pm 7,6$ & $16,2 \pm 5,0$ & $32,9 \pm 9,1$ \\
\hline 10 & $4,0 \pm 3,9$ & $6,3 \pm 3,6$ & $10,3 \pm 4,2$ & $13,4 \pm 6,7$ & $9,0 \pm 7,6$ & $22,4 \pm 12,1$ \\
\hline 12 & $6,6 \pm 5,2$ & $6,4 \pm 2,6$ & $13,0 \pm 5,2$ & $4,3 \pm 6,4$ & $16,4 \pm 2,5$ & $20,7 \pm 4,9$ \\
\hline 14 & $5,6 \pm 5,9$ & $9,3 \pm 8,0$ & $14,9 \pm 13,7$ & $7,1 \pm 6,5$ & $13,3 \pm 5,3$ & $20,4 \pm 10,6$ \\
\hline 16 & $2,8 \pm 1,5$ & $5,2 \pm 2,4$ & $8,0 \pm 3,1$ & $7,3 \pm 2,5$ & $14,9 \pm 1,8$ & $22,2 \pm 1,6$ \\
\hline 18 & $6,3 \pm 2,8$ & $9,6 \pm 4,4$ & $15,9 \pm 6,5$ & $5,4 \pm 2,1$ & $12,9 \pm 2,5$ & $18,3 \pm 3,9$ \\
\hline 20 & $2,4 \pm 2,9$ & $10,7 \pm 6,2$ & $13,1 \pm 8,9$ & $5,7 \pm 2,1$ & $13,7 \pm 2,3$ & $19,4 \pm 2,4$ \\
\hline 22 & $5,3 \pm 2,9$ & $9,6 \pm 2,2$ & $15,9 \pm 4,1$ & $10,1 \pm 5,1$ & $14,7 \pm 2,9$ & $24,9 \pm 5,7$ \\
\hline 24 & $4,0 \pm 3,2$ & $10,0 \pm 3,6$ & $14,1 \pm 3,6$ & $4,3 \pm 2,1$ & $11,6 \pm 2,0$ & $15,9 \pm 2,2$ \\
\hline
\end{tabular}

AE - Amebócitos estrelados

ANE - Amebócitos não estrelados AT - Amebócitos totais

Tabela 4 - Número médio de amebócitos circulantes em B. tenagophila dos grupos 3 e 4 .

\begin{tabular}{|c|c|c|c|c|c|c|}
\hline \multirow{2}{*}{$\begin{array}{l}\text { Intervalo } \\
\text { (horas) }\end{array}$} & \multicolumn{3}{|c|}{ Grupo 3} & \multicolumn{3}{|c|}{ Girupo 4} \\
\hline & $\mathrm{AE}$ & ANE & AT & $\overline{\mathrm{AE}}$ & ANE & AT \\
\hline$\overline{0,5}$ & $3,3 \pm 1,9$ & $7,9 \pm 4,0$ & $11,2 \pm 4,9$ & $6,7 \pm 9,7$ & $21,6 \pm 5,6$ & $28,3 \pm 10,2$ \\
\hline 2 & $6,3 \pm 5,1$ & $8,6 \pm 4,2$ & $14,9 \pm 8,8$ & $6,6 \pm 10,6$ & $31,7 \pm 11,5$ & $38,3 \pm 14,2$ \\
\hline 4 & $5,7 \pm 3,6$ & $5,9 \pm 2,1$ & $11,6 \pm 5,2$ & $2,1 \pm 2,3$ & $34,1 \pm 14,4$ & $36,2 \pm 12,8$ \\
\hline 6 & $5,6 \pm 5,9$ & $9,3 \pm 8,0$ & $14,9 \pm 13,8$ & $75,1 \pm 16,5$ & $33,1 \pm 7,1$ & $48,2 \pm 15,8$ \\
\hline 8 & $4,0 \pm 3,9$ & $6,3 \pm 3,6$ & $10,3 \pm 4,4$ & $5,8 \pm 5,8$ & $32,4 \pm 5,3$ & $37,7 \pm 9,6$ \\
\hline 10 & $4,7 \pm 2,9$ & $6,7 \pm 3,0$ & $11,4 \pm 4,6$ & $9,3 \pm 8,4$ & $19,1 \pm 8,4$ & $28,4 \pm 7,8$ \\
\hline 12 & $3,6 \pm 2,3$ & $4,2 \pm 2,1$ & $7,8 \pm 3,1$ & $9,1 \pm 4,7$ & $18,1 \pm 7,7$ & $27,2 \pm 8,6$ \\
\hline 14 & $10,4 \pm 8,1$ & $8,1 \pm 8,0$ & $18,6 \pm 14,1$ & $2,4 \pm 2,3$ & $29,2 \pm 17,3$ & $31,6 \pm 17,8$ \\
\hline 16 & $6,9 \pm 2,5$ & $9,3 \pm 4,9$ & $16,2 \pm 6,5$ & $2,6 \pm 1,9$ & $36,4 \pm 9,1$ & $39,0 \pm 7,9$ \\
\hline 18 & $15,8 \pm 13,5$ & $11,0 \pm 7,9$ & $26,8 \pm 20,7$ & $2,4 \pm 0,7$ & $21,4 \pm 11,4$ & $23,8 \pm 11,0$ \\
\hline 20 & $3,7 \pm 2,8$ & $8,9 \pm 4,9$ & $12,6 \pm 3,9$ & $5,1 \pm 3,9$ & $14,4 \pm 4,1$ & $19,6 \pm 3,9$ \\
\hline 22 & $5,0 \pm 2,3$ & $6,6 \pm 3,8$ & $11,6 \pm 5,1$ & $6,3 \pm 5,9$ & $14,9 \pm 6,2$ & $21,2 \pm 8,3$ \\
\hline 24 & $6,1 \pm 2,9$ & $6,4 \pm 3,3$ & $12,5 \pm 4,6$ & $10,3 \pm 4,3$ & $20,6 \pm 13,0$ & $30,9 \pm 10,0$ \\
\hline
\end{tabular}

AE - Amebócitos estrelados

ANE - Amebócitos nāo estrelados

AT - Amebocitos totais

Tabela 5 - Número médio de amebócitos circulantes em B. tenagophila dos grupos 5 e 6 .

\begin{tabular}{|c|c|c|c|c|c|c|}
\hline \multirow{2}{*}{$\begin{array}{l}\text { Intervalo } \\
\text { (horas) }\end{array}$} & \multicolumn{3}{|c|}{ Grupo 5} & \multicolumn{3}{|c|}{ Grupo 6} \\
\hline & $\overline{\mathrm{AE}}$ & ANE & AT & $\mathrm{AE}$ & ANE & AT \\
\hline$\overline{0,5}$ & $0,9 \pm 0,7$ & $10,9 \pm 4,5$ & $11,8 \pm 5,1$ & $6,4 \pm 3,3$ & $8,7 \pm 3,4$ & $15,1 \pm 4,1$ \\
\hline 2 & $2,4 \pm 2,9$ & $10,7 \pm 6,2$ & $13,8 \pm 8,9$ & $4,0 \pm 3,2$ & $10,1 \pm 3,6$ & $14,1 \pm 3,6$ \\
\hline 4 & $1,9 \pm 1,3$ & $8,4 \pm 4,1$ & $10,3 \pm 4,9$ & $7,6 \pm 5,4$ & $16,3 \pm 4,5$ & $23,9 \pm 2,3$ \\
\hline 6 & $3,9 \pm 3,6$ & $15,4 \pm 5,8$ & $19,3 \pm 8,4$ & $11,1 \pm 1,5$ & $11,6 \pm 3,8$ & $22,7 \pm 4,0$ \\
\hline 8 & $2,4 \pm 2,1$ & $7,3 \pm 2,9$ & $9,7 \pm 4,6$ & $16,3 \pm 2,3$ & $15,7 \pm 5,6$ & $32,0 \pm 6,5$ \\
\hline 10 & $4,6 \pm 2,9$ & $7,1 \pm 2,8$ & $11,7 \pm 4,5$ & $7,0 \pm 4,0$ & $9,0 \pm 5,0$ & $16,0 \pm 3,9$ \\
\hline 12 & $7,4 \pm 3,6$ & $16,6 \pm 4,2$ & $24,0 \pm 4,0$ & $7,7 \pm 2,3$ & $7,4 \pm 3,8$ & $15,1 \pm 3,5$ \\
\hline 14 & $17,0 \pm 3,3$ & $15,9 \pm 6,8$ & $32,9 \pm 4,2$ & $14,7 \pm 4,4$ & $10,9 \pm 5,2$ & $25,6 \pm 4,7$ \\
\hline 16 & $30,9 \pm 9,8$ & $33,1 \pm 3,5$ & $64,0 \pm 4,1$ & $22,0 \pm 3,2$ & $11,6 \pm 3,7$ & $33,6 \pm 3,7$ \\
\hline 18 & $10,3 \pm 4,5$ & $15,6 \pm 5,6$ & $25,9 \pm 9,4$ & $7,7 \pm 4,3$ & $24,3 \pm 4,7$ & $32,0 \pm 3,9$ \\
\hline 20 & $4,9 \pm 3,4$ & $15,7 \pm 3,8$ & $20,6 \pm 5,1$ & $1,4 \pm 1,6$ & $22,9 \pm 3,6$ & $24,3 \pm 4,5$ \\
\hline 22 & $6,1 \pm 2,3$ & $14,0 \pm 4,8$ & $20,1 \pm 4,1$ & $31,9 \pm 3,7$ & $11,4 \pm 3,9$ & $43,3 \pm 4,7$ \\
\hline 24 & $2,3 \pm 2,1$ & $13,6 \pm 4,9$ & $15,9 \pm 5,6$ & $20,3 \pm 2,7$ & $13,7 \pm 3,5$ & $34,0 \pm 4,1$ \\
\hline
\end{tabular}

$\mathrm{AE}$ - Amebocitos estrelados

ANE - Amebócitos nāo estrelados

AT - Amebócitos totais 
Tabela 6 - Número médio de amebócitos circulantes em $B$. tenagophila dos grupos 7 e 8 .

\begin{tabular}{|c|c|c|c|c|c|c|}
\hline \multirow{2}{*}{$\begin{array}{l}\text { Intervalo } \\
\text { (horas) }\end{array}$} & \multicolumn{3}{|c|}{ Grupo 7} & \multicolumn{3}{|c|}{ Grupo 8} \\
\hline & $\overline{\mathrm{AE}}$ & ANE & $\overline{A T}$ & $\overline{A E}$ & ANE & $\overline{\mathrm{AT}}$ \\
\hline 0,5 & $2,6 \pm 1,5$ & $11,0 \pm 3,2$ & $13,6 \pm 2,9$ & $4,3 \pm 2,1$ & $11,6 \pm 1,9$ & $15,9 \pm 2, \overline{1}$ \\
\hline 2 & $2,6 \pm 2,2$ & $14,4 \pm 4,4$ & $17,0 \pm 3,1$ & $5,7 \pm 2,1$ & $13,7 \pm 2,3$ & $19,4 \pm 2,4$ \\
\hline 4 & $2,0 \pm 0,8$ & $12,3 \pm 3,1$ & $14,3 \pm 3,3$ & $5,4 \pm 2,1$ & $12,9 \pm 2,5$ & $18,3 \pm 3,9$ \\
\hline 6 & $6,9 \pm 3,6$ & $9,7 \pm 3,5$ & $16,6 \pm 2,7$ & $7,3 \pm 2,1$ & $14,9 \pm 1,8$ & $22,2 \pm 4,2$ \\
\hline 8 & $10,0 \pm 4,0$ & $13,4 \pm 2,8$ & $23,4 \pm 3,5$ & $7,1 \pm 6,5$ & $13,3 \pm 5,3$ & $20,4 \pm 10,6$ \\
\hline 10 & $13,7 \pm 3,8$ & $26,3 \pm 4,2$ & $40,0 \pm 2,2$ & $4,3 \pm 2,6$ & $16,4 \pm 2,5$ & $20,7 \pm 4,9$ \\
\hline 12 & $49,9 \pm 12,5$ & $27,4 \pm 12,4$ & $76,5 \pm 22,9$ & $10,1 \pm 5,1$ & $14,7 \pm 2,8$ & $24,8 \pm 5,7$ \\
\hline 14 & $25,4 \pm 4,7$ & $23,9 \pm 4,9$ & $49,3 \pm 1,7$ & $13,4 \pm 6,7$ & $9,0 \pm 7,6$ & $22,4 \pm 12,1$ \\
\hline 16 & $33,7 \pm 7,1$ & $24,4 \pm 5,9$ & $58,1 \pm 2,6$ & $16,1 \pm 7,1$ & $14,0 \pm 7,3$ & $30,1 \pm 10,9$ \\
\hline 18 & $30,0 \pm 2,3$ & $20,7 \pm 4,2$ & $50,7 \pm 3,1$ & $21,1 \pm 10,4$ & $15,1 \pm 9,1$ & $36,2 \pm 9,4$ \\
\hline 20 & $29,4 \pm 6,5$ & $23,1 \pm 5,1$ & $52,5 \pm 3,0$ & $25,7 \pm 9,1$ & $12,0 \pm 5,8$ & $37,3 \pm 7,3$ \\
\hline 22 & $25,6 \pm 7,3$ & $24,4 \pm 7,8$ & $50,0 \pm 1,4$ & $17,9 \pm 3,0$ & $15,4 \pm 4,9$ & $33,3 \pm 4,5$ \\
\hline 24 & $30,4 \pm 7,9$ & $22,1 \pm 5,2$ & $52,5 \pm 3,6$ & $20,0 \pm 7,9$ & $13,3 \pm 5,3$ & $33,3 \pm 9,2$ \\
\hline
\end{tabular}

$A E$ - Amebócitos estrelados

ANE - Amebócitos năo estrelados

AT - Amebócitos totais

Tabela 7 - Número médio de amebócitos circulantes em $B$. tenagophila dos grupos 9 e 10 .

\begin{tabular}{|c|c|c|c|c|c|c|}
\hline \multirow{2}{*}{$\begin{array}{l}\text { Intervalo } \\
\text { (horas) }\end{array}$} & \multicolumn{3}{|c|}{ Grupo 9} & \multicolumn{3}{|c|}{ Grupo 10} \\
\hline & $\overline{\mathrm{AE}}$ & ANE & $\overline{\mathrm{AT}}$ & $\mathrm{AE}$ & ANE & AT \\
\hline $\begin{array}{l}0,5 \\
2 \\
4 \\
6 \\
8 \\
10 \\
12 \\
14 \\
16 \\
18 \\
20 \\
22 \\
24\end{array}$ & $\begin{array}{l}2,9 \pm 5,1 \\
2,4 \pm 1,9 \\
2,9 \pm 2,9 \\
3,4 \pm 4,1 \\
3,1 \pm 2,3 \\
6,1 \pm 4,5 \\
5,3 \pm 2,9 \\
18,6 \pm 10,5 \\
6,7 \pm 2,5 \\
12,3 \pm 4,6 \\
10,4 \pm 4,4 \\
27,6 \pm 4,9 \\
13,7 \pm 7,3\end{array}$ & $\begin{array}{l}8,7 \pm 5,6 \\
7,1 \pm 3,7 \\
7,3 \pm 2,7 \\
7,6 \pm 2,9 \\
5,4 \pm 2,8 \\
13,0 \pm 7,1 \\
11,0 \pm 4,6 \\
8,3 \pm 9,1 \\
6,7 \pm 3,7 \\
12,6 \pm 3,9 \\
22,6 \pm 4,4 \\
15,9 \pm 5,6 \\
11,9 \pm 3,8\end{array}$ & $\begin{array}{l}11,6 \pm 10,4 \\
9,5 \pm 4,2 \\
10,2 \pm 3,8 \\
11,0 \pm 6,5 \\
8,5 \pm 4,5 \\
19,1 \pm 10,9 \\
16,3 \pm 4,7 \\
26,9 \pm 18,1 \\
13,4 \pm 4,2 \\
24,9 \pm 5,8 \\
33,0 \pm 7,2 \\
43,5 \pm 8,9 \\
25,6 \pm 4,9\end{array}$ & $\begin{array}{l}3,4 \pm 2,2 \\
4,6 \pm 4,5 \\
3,1 \pm 2,1 \\
3,4 \pm 1,7 \\
1,7 \pm 1,4 \\
10,0 \pm 3,3 \\
62,1 \pm 17,6 \\
46,0 \pm 17,5 \\
27,7 \pm 10,6 \\
19,4 \pm 9,1 \\
12,4 \pm 6,9 \\
6,7 \pm 3,3 \\
7,0 \pm 2,5\end{array}$ & $\begin{array}{l}7,1 \pm 2,9 \\
10,1 \pm 6,3 \\
9,0 \pm 2,3 \\
11,1 \pm 4,7 \\
6,3 \pm 3,1 \\
8,6 \pm 10,4 \\
13,7 \pm 6,7 \\
23,9 \pm 13,0 \\
19,3 \pm 11,9 \\
11,9 \pm 6,0 \\
4,6 \pm 4,5 \\
4,6 \pm 2,5 \\
4,9 \pm 3,7\end{array}$ & $\begin{array}{l}10,5 \pm 4,6 \\
14,7 \pm 10,3 \\
12,1 \pm 4,3 \\
14,5 \pm 4,9 \\
8,0 \pm 3,1 \\
18,6 \pm 10,8 \\
75,8 \pm 20,9 \\
69,9 \pm 24,3 \\
47,0 \pm 18,8 \\
31,1 \pm 11,9 \\
17,0 \pm 10,5 \\
11,3 \pm 4,7 \\
11,9 \pm 4,7\end{array}$ \\
\hline
\end{tabular}

AE - Amebócitos estrelados

ANE - Amebócitos nāo estrelados

AT - Amebócitos totais

Não houve diferença significativa da taxa de penetração dos miracídios entre os diversos grupos.

\section{Discussăo e Conclusão}

Nos experimentos foram observados dois tipos de mecanismos de defesa nos moluscos; um provavelmente de natureza de predomínio celular (grupo 5) e outro provavelmente de natureza de predomínio humoral (grupos 7, 9 e 10). Loker e col. ${ }^{10}$ (1986) admitiram a presença de fatores humorais na hemolinfa quando obtiveram destruiçāo "in vitro" de esporocistos de S. mansoni, utilizando hemolinfa de $B$. glabrata infectada com Echinostoma paraensei. A reaçāo predominantemente celular só ocorreu quando se inoculou hemolinfa de moluscos infectados por $S$. mansoni anteriormente à infecção por este trematódeo, fazendo crer que este tipo de reação envolve mecanismos específicos. Bayne e col. ${ }^{1}$ (1985) verificaram que os componentes da hemolinfa que induzem a defesa celular em $B$. glabrata são aglutininas que desempenham papel de anticorpos específicos.

B. tenagophila, inoculadas com hemolinfa de moluscos infectados por furcocercárias longifurcadas sem ocelos, apresentaram elevada resistência à infecçāo posterior por $S$. mansoni. Sullivan e col. ${ }^{13}$ (1982) haviam observado $B$. glabrata resistentes à infecção por $S$. mansoni quando infectadas por miracídios irradiados de Riberoia marine. B. tenagophila inoculadas com hemolinfa de moluscos livres 
de infecçāo, antes ou após à exposição ao S. mansoni, apresentaram significativo aumento da suscetibilidade à infecção esquistossomótica quando comparadas ao grupo-controle infectado. Este mesmo fato ocorreu nos moluscos expostos ao $S$. mansoni e posteriormente inoculados com hemolinfa de caramujos infectados com distomoxifidiocercárias. Esses efeitos poderiam ter sido provocados por mecanismos de imunodepressão.

A resistência à infecçāo pelo $S$. mansoni resultou sempre em maior destruiçāo dos esporocistos, quer por mecanismos predominantemente celular ou humoral e foi provocada pela inoculação prévia de hemolinfa de moluscos parasitados por furcocercárias: furcocercária do $S$. mansoni (quando houve imunidade predominantemente celular) e furcocercária longifurcada sem ocelos (quando houve imunidade predominantemente humoral).

A precocidade da reação amebocitária pareceu ser fator importante no sucesso do combate à infecção.

Os presentes resultados sugerem que moluscos parasitados por digenéticos, que produzem cercárias de caudas bifurcadas, devem possuir antígenos comuns que induzem resistência cruzada à infecção por trematódeos do mesmo grupo. Esse fato tem grande importância epidemiológica pois, em criadouros que contenham grande quantidade de planorbídeos parasitados por outros digenéticos com furcocercárias, o número de caramujos infectados por $S$. mansoni deverá estar reduzido.

\section{Referências Bibliográficas}

1. BAYNE, C. J.; BOSWELL, C. A.; LOKER, E. S.; YLI, M. A. Plasma components which mediate cellular defences in the grastropod mollusc Biomphalaria glabrata. Dev, Comp. Immunol., 2: 523-30, 1985.

2. FISHER, R. C. A study in insect multiparasitism. II. The mechanism and control of competition for posesion of the host. J. Exp. Biot., 38: 605-28, 1961.
3. LIE, K. J. \& HEYNEMAN, D. Studies on resistance in snails. A specific tissue reaction to Echinostoma lindoense in Biomphalaria glabrata snail. J. Parasitol. 5: 621-6, 1975

4. LIE, K. J.; HEYNEMAN, D; YAU, P. The origin of amebocytes in Biomphaloria glabrata. J. Parasitol, 61: 574-6, 1975 .

5. LIE, K. J. \& HEYNEMAN, D. Studies on resistance in snails. V. Tissue reactions to Echinostoma lindoense in naturally resistance Biomphalaria glabrata. J. Parasitol., 62: 2927. 1976a.

6, LIE, K. J. \& HEYNEMAN, D. Studies on resistance in snails. VI. Escape of Echinosstoma lindoense sporocysts from encapsulation in the snails heart and subsequent loss of the host's ability to resist infection by same parasite. $J$. Parasitol., 62: 298-303, 1976 b.

7. LIE, K. J.; JEONG, K. H.; HEYNEMAN, D, Tissue reactions induced by Schistosoma mansoni in Biomphalaria glabrata. Ann. Trop. Med. Parasitol, 74: 157-66, 1980.

8. LIE, K. J. Survival of Schistosoma mansoni and other trematode larvas in Biompholaria glabrata: a discussion of interference theory. Trop. Geogr. Med., 34: 111-22, 1982.

9. LIM, H. \& HEYNEMAN, D. Intramolluscan inter-trematode antagonism: a rewiew on factors influencing the hostparasite sistem and its possible role in biological control. Adv. Parasitol., 10: 191-268, 1972.

10. LOKER, E. S.; BAYNE, C. J.; YUI, M. A. Echinostoma paraensei: bemocytes of Biomphalaria glabrata as targets of Echinostoma mediate interference with host snails resistance to Schistosoma mansoni. Exp. Parasitol., 62: $149-54,1986$

11. MACHADO, S. M. P,; MAGALHÄES, L. A.; ARTIGAS, P. T.; CORDEIRO, N. S.; CARVALHO, J. F. Verificaçāo do antagonismo entre larvas de Schistosoma mansoni e larvas de outros Digenea em Biomphalaria tenagophila mulusco planorbideo de criadouro natural situado na regiāo de Campinas, SP. Rev. Saúde Pública, 22: 484-8, 1988

12. SANTANA, J. V.; MAGALHĀES, L. A.; RANGEL, H. A. Nota sobre a quantificaçâo da atividade fagocitária de amebócitos de moluscos Biomphalaria glabrata livres de infecçăo e infectados por Schistosoma mansoni. São Paulo, In: Congresso da Sociedade Brasileira Medicina Tropical, $21^{\circ}$, Sāo Paulo. p.63, 1985.

13.SULLIVAN, J. T.; RICHARDS, C.; LIE, K. J.; HEYNEMAN, D. Riberoia marini: irradiated miracidia and induction of adquired resistance in Biomphalaria glabrata. Exp. Parasitol., 53: 17-25, 1982.

\section{Abstract}

The resistance of B. tenagophila snails to infection by Schistosoma mansoni was studied. These snails had been previously inoculated with hemolymph taisen from other snails infected by $S$. mansoni of SJ strain or by other trematodes. The findings suggest that two types - cellular and humoral - are responsible for the resistance to infection by S. mansoni. The cellular response occurred when the snalls were inoculated with hemolymph from snails infected by $S$. mansoni. B. tenagophila inoculate with hemolymph from snails infected by furcocercariae without eys-spot, also showed resistance to the infection by S.mansoni. In this latter case, the degenerated sporocysts were not enveloped by amebocitary reaction, leading to the conciusion that humoral factors could be involved. 